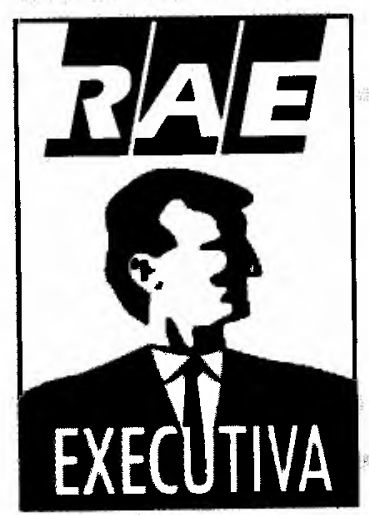

\title{
POR QUE OS PROGRAMAS DE QUALIDADE FALHAM?
}

*Jose Tolovl Jr:

Quais as causas de insucesso em programas de qualidade? Este artigo analisa situações reais e oferece sugestões de superação.

Which are the failure causes in quality programs? This article analyses actual situations and offers suggestions to overcome them.

\section{"palavas-ghave}

Dualidade, gestắo da qualidade total, planejamento para a qualidade, motivaçäo para a qualidade.

\section{"KeY WORDS:}

Quality, total quality management, planning for quality, motivation for quality.
Parece que não existem mais dúvidas sobre se qualidade é bom ou não. As empresas não falam de outra coisa! Segundo Paul Osterman ${ }^{1}$ do MIT (Massachussets Institute of Tecnology), aproximadamente $80 \%$ das empresas americanas, nos mais variados setores, adotaram alguma forma de círculos de qualidade, qualidade total $\left(\mathrm{TQM}^{2}\right)$, gestão baseada em equipes, ou alguma combinação entre elas.

Além disso, observamos também uma verdadeira febre de certificações nas nor-

"Professor do GVPEC da EAESPI FGV $\theta$ do PDG-EXEC da Sociedado de Desenvolvimento Empresarial.

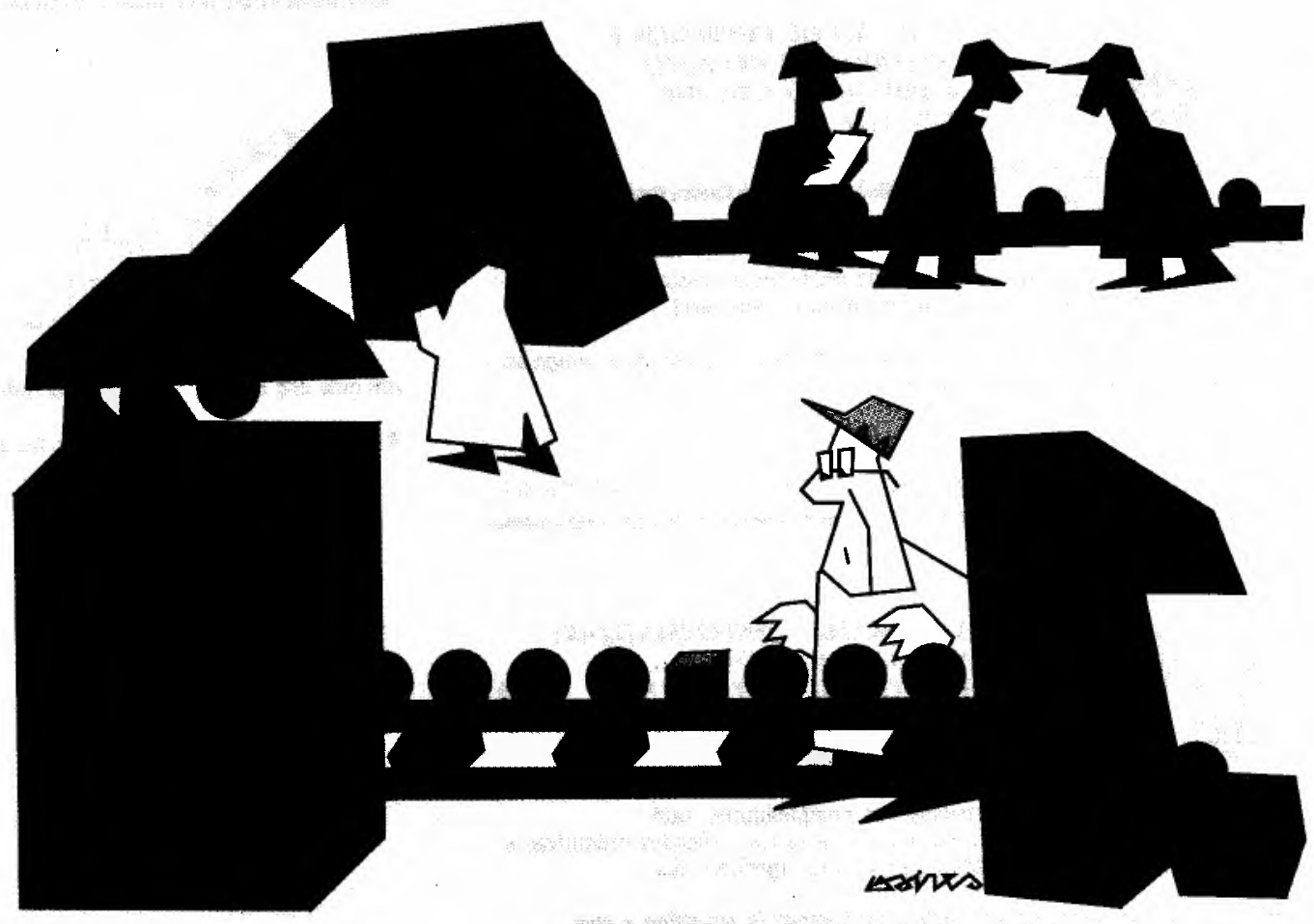


mas ISO 9000, o que poderia nos indicar que nossas organizações estão cada vez mais "qualificadas", ou seja, trabalham com melhor qualidade.

Contudo, quando nos aproximamos mais das pessoas que fazem, ou deveriam fazer, qualidade, nem sempre encontramos aquilo que lemos nos jornais e revistas. As pessoas se queixam que seu programa não é bem o que é publicado; que o nível de qualidade na empresa melhorou, mas está longe do que poderia ou deveria ser; que a direção da empresa, na verdade, não se importa com qualidade; que estão perdendo tempo com um programa que não está levando a lugar algum; e assim por diante.

São familiares essas frases? Temos certeza que já as ouviram, e, recentemente! O que está, então, acontecendo com nossos programas de qualidade? Por que alguns funcionam maravilhosamente enquanto outros parecem apenas uma perda de tempo e dinheiro?

Vamos analisar os vários aspectos ou situaçōes que têm levado inúmeras organizações (infelizmente mais que o desejável!) a situações de insucesso em sua busca pela qualidade.

\section{NÃO-ENVOLVIMENTO DA ALTA DIREÇÃO}

Mais uma vez voltamos ao decantado envolvimento da alta direção. Não devemos ter assunto tão falado quanto o fracasso de programas de mudança pelonãoenvolvimento da alta administração. Qualidade é um programa de mudanças comportamentais, portanto, estamos, e estaremos sempre, falando de pessoas. Mudanças comportamentais exigem alto esforço, dedicação e perseverança, $\mathrm{e}$ isto tem que vir do topo da organização. Davis e Lawrence ${ }^{3}$ nos mostram níveis de dificuldade crescentes ao se tentar transformar uma organização para incorporar ações "matriciais" tão características dos programas de qualidade. Estas dificuldades estão na seguinte ordem: estrutura, sistemas, comportamento e cultura. Ao se falar em qualidade, estamos abordando os níveis mais complexos, e, portanto, mais difíceis de serem manipulados, de comportamento e cultura.
Temos observado que os principais executivos, ou os donos, das organizações que se interessam por qualidade, na verdade, estão mais interessados com o modismo do que com as verdadeiras implicações e consequiências de um tal programa. Para não sermos totalmente injustos, alguns

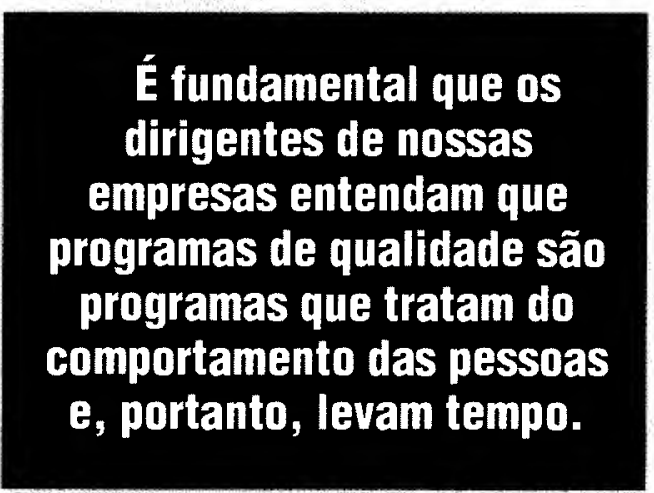

estão interessados nos efeitos de bottom line (afinal, como se diz isto em português?) de seus programas, o que é perfeitamente compreensível, sem contudo se darem conta que estão lidando com comportamento, com pessoas, com interesses pessoais e com (des)equilibrios de poder.

E inútil, vamos repetir, é inútil, tentar iniciar programas de qualidade sem o verdadeiro interesse da alta administração. Temos constantemente dito a empresas, que pensam em se iniciar no modismo da qualidade, que desistam temporariamente da idéia até que, realmente, seus dirigentes sintam que isto traz dividendos e sucésso. Se os dirigentes não pensam assim, ou melhor, não acreditam nisto, um programa educacional talvez seja a melhor solução para um início de processo de mudança. Em uma empresa média do setor de serviços financeiros chegamos a sugerir a interrupção de um programa de qualidade pela "falta de tempo" do presidente em acompanhar e se envolver.

Atenção! Com comprometimento não estamos simplesmente falando em "pagar a conta". Estamos falando em realmente querer que algo de diferente ocorra em suas empresas. Estamos falando em "gastar tempo" com o programa de qualidade, em conversar com colaboradores", mostrando-lhes que a qualidade é algo que é bom para todos: para os clientes,
1. Business Week, Oct. 17 1994.

2. TOM - Total Ouality Management ou, em portugues, Gestấo da Qualidade Total.

3. DAVIS, Stanley M., LAWRENCE, Paul. Matrix. Mass.: Addison Wesley 0. D. Series, 1977.

4. A maloria das empresas pretere o termo funcionários ou empregados. Recentemente outras empresas ja estão se reforindo a parceiros, talentos humanos ou mesmo seres humanos (III), em contraposicto a recursos humanos. 
para a empresa, para os colaboradores e para a sociedade. Isto só é viável com o real interesse e entendimento que qualidade é bom e traz retornos para a organiżação.

\section{Ansiedade por resultados}

E fundamental que os dirigentes de nossas empresas entendam que programas de qualidade são progxamas que tratam do comportamento das pessoas e, portanto, levam tempo. Temos vivenciado vários casos de ansiedade por resultados que levam ao insucesso de programas bem iniciados, simplesmente porque as pessoas não têm a paciência adequada ao tipo de projeto que estão conduzindo.

Ouvimos, no Japão, frases como "Nosso programa de qualidade está muito no início; só o iniciamos há seis anos!" É claro que estamos no Ocidente e nossa cultura (ou paciência) é diferente, mas temos que ter consciência de que os primeiros resultados demoram a surgir. Provavelmente nada ocorrerá antes de um ano, e talvez os primeiros resultados sejam modestos. Mas as empresas que têm trabalhado com perseverança têm provado que a espera vale a pena. E também que a soma de pequenos resultados pode trazer grandes benefícios para a organização.

É fundamental que se tenha em mente a necessidade de superar a fase inercial inicial. Em uma gráfica de grande porte passamos um ano em eternas discussões sobre os efetivos resultados do projeto de qualidade em implantação. Em um determinado momento, e isto tem se repetido inúmeras vezes, os resultados começaram a aparecer e as discussões sobre resultados tomaram outra forma, bem mais saudável.

Além da ansiedade por resultados a curto prazo, outra situação que leva ao aborto de inúmeros programas de qualidade é a expectativa exagerada dentro das empresas. O processo de implantação da qualidade é gradual. Gradual e crescente, de tal forma que é preciso entender em que fase da curva de desenvolvimento estamos.

A qualidade não acontece por conta própria. É um contínuo envolvimento de pessoas que, no início parece inócuo, mas no decorrer do tempo, e se o processo for continuamente estimulado, apresenta resultados crescentes e cada vez mais surpreendentes.

\section{Desinteresse do nível gerencial}

"A grande popularidade dos programas de qualidade tem impedido que o nivel gerencial das organizaçōes entenda profundumente sua ideologia e conseqüências" ${ }^{\prime 2}$. Esta frase nos
5. GRANT, R, M., SHANI, R., KRISHNAN, R. TOM'S Challenge to Management - theory and practice. Sloan Management Review, Winter 1994.

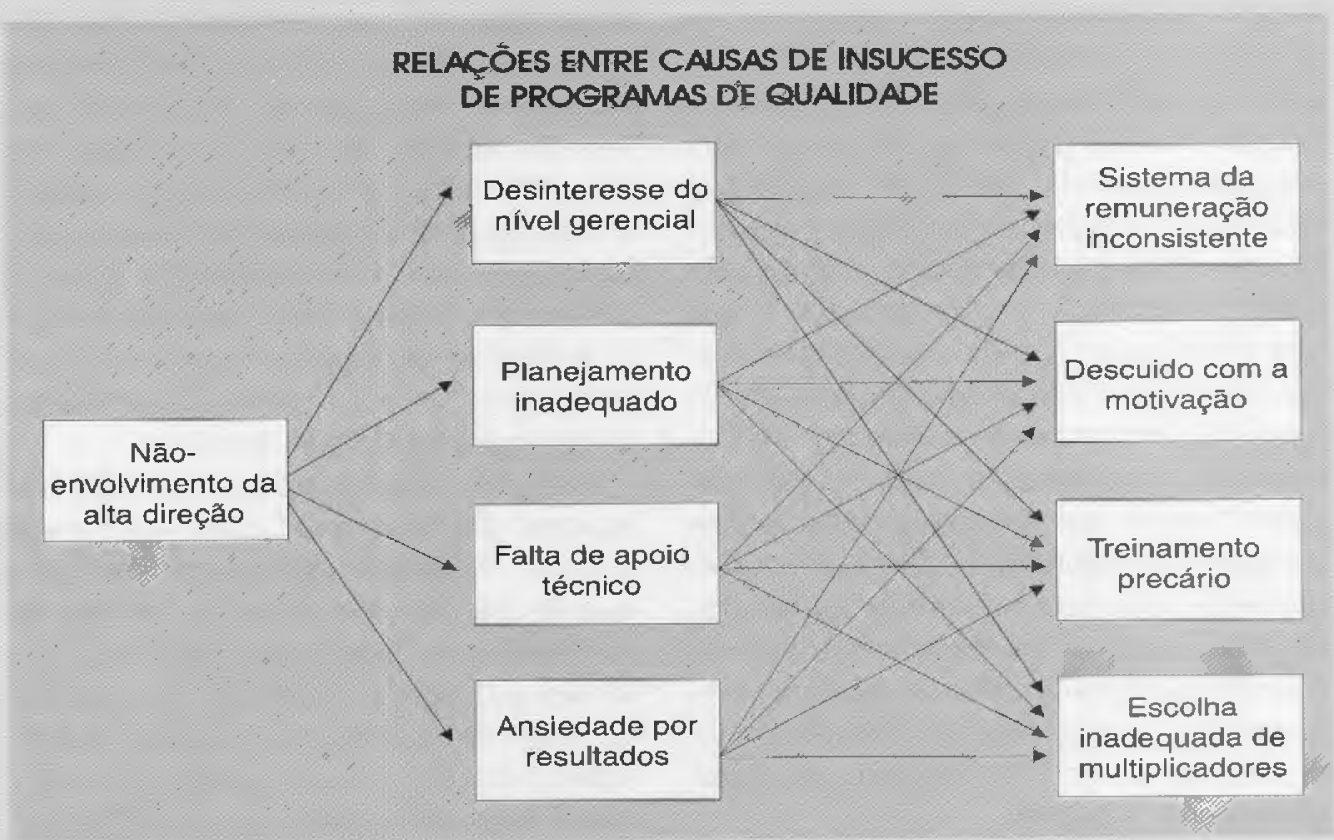


oferece, talvez, uma boa indicação do que. pode ocorrer com o nível gerencial das empresas. Não se questiona a qualidade, mas, muitas vezes, também não se entra no íntimo da questão. Se o envolvimento da alta administração é básico para o sucesso, o do nível gerencial é crucial para sua sustentação.

Não basta a vontade do presidente, é preciso que ele tenha suporte de todas as camadas organizacionais pois, mais uma vez, programas de qualidade são programas de envolvimento e comprometimento de pessoas. O nível gerencial tende a achar que qualidade é algo óbvio e que, portanto, não necessita de grande energia ou dedicação. Sem dúvida, este é o caminho certo para grandes dificuldades na implantação.

Acompanhamos, recentemente, uma grande empresa industrial de processos sofrer uma enorme dificuldade em desenvolver seu programa de qualidade e de certificação ISO, apesar de ter seu presidente e principal executivo como principal patrocinador. Somente quando os outros níveis gerenciais da organização assumiram seu papel no processo, a qualidade começou a trazer os benefícios anteriormente projetados.

\section{Planejamento inadequado}

A implantação da qualidạde é sempre um projeto de longo prazo, e, portanto, não prescinde de um bom planejamento. Mais uma vez, como o conceito de qualidade parece óbvio e evidente para todos, muitas empresas partem diretamente para a execução, sem se preocuparem muito com o planejamento. Para sermos sinceros, ainda é melhor esta atitude de sair executando do que nada fazer. Contudo, à medida que o tempo passa, e as exigências por níveis superiores de qualidade aparecem, a falta de um planejamento adequado pode levar a situações indesejáveis, à insegurança e ao insucesso de um caminho ${ }^{6}$ que vinha sendo trilhado.

É inútil insistir sobre os benefícios do planejamento. Convém, no entanto, ressaltar que a implantação da qualidade é um processo bastante complexo com muitas incertezas e ambiguiidades. Isto poderia nos sugerir que nestas condições não há o que planejar. Afirmamos que se trata justamente do contrário. Um bom planejamento poderá nos dar as bases de comparação para saber se estamos ou não indo no rumo certo e se devemos corrigir nossa rota de tempos em tempos. O exercício do planejamento para programas de qualidade deve incluir metas, treinamento, metodologia a ser aplicada, velocidade de implantação, áreas a serem abordadas e pessoas envolvidaş. Essa abrangência, por si só, mostra-nos os riscos que podemos correr se não dermos a devida importância ao planejamento.

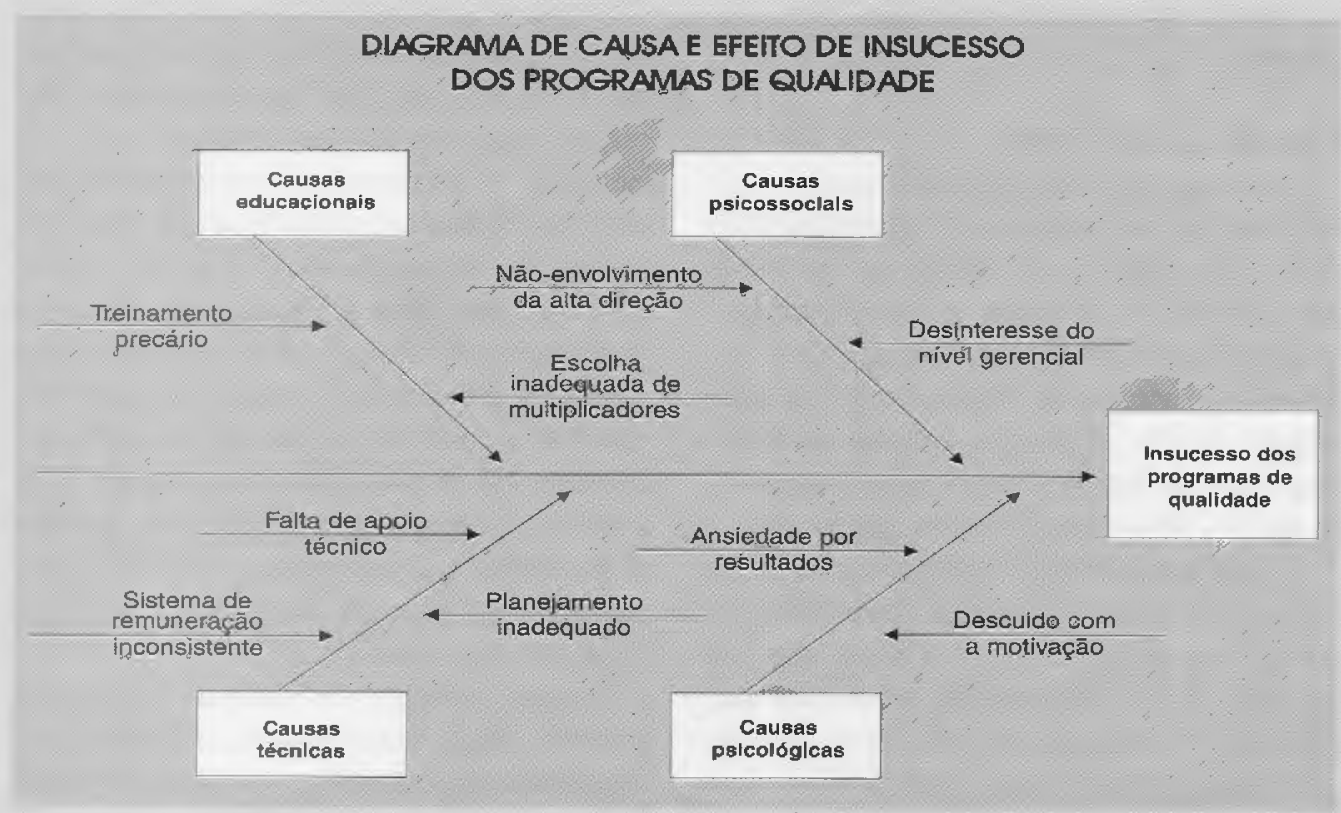

6. Não se pode falar de um programa formal de qualidade nesta situação de ausência de planejamento! 
7. ISHIKAWA, K. Atividades do Círculo de CQ. Controle de Oualidade Total. Rio de Janeiro: Campus, 1993.

8. KUME, H. Mótodos estat/sticos para melhoria da qualidade. Sžo Paulo: Gente $\theta$ AOTS, 1993.

9. ISHIKAWA, Op. cit., OSADA T. The 5 S's five keys to a total quality environment. Tokyo: Asian Productivity Organization 1991; SHIOZAWA, R.S.C. OuaIldade no atendimento e tecnologia de Informação. São Paulo: Atias, 1993.

10. KUME, H. Op. cit.

11. Sempre é bom relembrar os conceitos de higiene e motivacão de HERZBERG, F., MAUSNER, B., SNYDERMAN, B. The motivation to work. New York: Wiley, 1959.

\section{Treinamento precário}

Um dos comentários mais freqüentes é que círculos de qualidade são coisas do passado, ou ainda, coisas que não funcionam. Muitas empresas colocam grupos de pessoas para discutirem problemas sem o menor preparo para tal.

Não é óbvio para as pessoas como se deve analisar problemas. Em geral, as pessoas nem sabem por onde começar. Qualquer tentativa de montagem de grupos de trabalho para se analisar problemas deve se iniciar com treinamento. Parece óbvio, mas não é o que se faz muitas vezes, atribuindo-se, depois, os maus resultados ao conceito e não à falta de preparação das pessoas.

E fundamental o estabelecimento de um programa de treinamento em solução de problemas ${ }^{7}$, treinamento em ferramentas estatísticas simples ${ }^{8}$, visitas a outras empresas, e estímulo ao autodesenvolvimento. E também importante que o treinamento tenha caráter contínuo e que os vários níveis organizacionais estejam envolvidos. Estes vários níveis organizacionais exigem tipos e programas de treinamen-

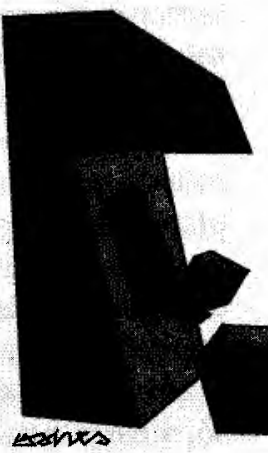
to diferenciados e específicos. $O$ desbalanceamento desta programação pode ser fatal para o bom andamento do programa.

\section{Falta de apoio técnico}

Como qualidade parece ser um conceito intuitivo, descuida-se com freqüência de seus aspectos mais técnicos. Existem metodologias testadas e comprovadas ${ }^{9}$ que facilitam enormemente e também aceleram o processo de implantação da qualidade. A não aplicação dessas metodologias pode facilmente levar ao descrédito de um programa bem-intencionado.

E preciso lembrar também que o conceito fundamental da qualidade está associado ao de melhorias contínuas ou, em japonês, kaizen. Melhorias contínuas significam o constante questionar e analisar problemas, e isto é uma questão que exige técnicas e métodos ${ }^{10}$. Já acompanhamos casos em que as pessoas envolvidas com a implantação da qualidade se sentiam frustradas e mesmo incapacitadas de seguir em frente sem entender bem o que estava ocorrendo. Este é quase sempre um indício da falta de apoio técnico, isto é, aquelas pessoas que já superaram seus limites de conhecimento e que carecem de técnicas que as auxiliem a sair da situação. Não estamos dizendo que o apoio técnico deva ser externo à organização. Freqüentemente este é o caminho mais curto, mas muitas empresas têm desenvolvido seus próprios técnicos com excelentes resultados.

\section{Sistema de remuneração inconsistente}

A questão da remuneração é sempre debatida e extremamente polêmica, particularmente em nosso país onde existem tantas diferenças salariais. Sabemos, e acreditamos, que a remuneração não é fator de motivação, mas de higiene ${ }^{11}$. No entanto, é preciso estar atento para as incoerências que podem se formar ao se estimular pessoas a trabalharem com qualidade.

Numa importante instituição educacional, um departamento conseguiu, de forma praticamente autônoma, desenvolver uma cultura de qualidade, o que ocasionou um diferencial notável na organização. Apesar deste diferencial, por ocasião de acordos e ajustes salariais, o diferencial de produtividade deste departamento não foi levado em consideração, apesar do efetivo ganho financeiro gerado para a instituição. Pode-se imaginar a frustração dos colaboradores deste departamento e da dificuldade de se manter os padrões de qualidade após esta incoerência claramente demonstrada pela instituição. Isto tem ocorrido com bastante freqüência; é um ponto de alerta para aqueles que querem perpetuar suas organizações com qualidade.

Vamos também nos lembrar de que, na maioria das organizações, o sistema de avaliação e, portanto, o de remuneração, 
está associado a um sistema de metas ou orçamentário, que quase nunca está associado ao programa de qualidade. Mais grave ainda é o fato que, em geral, os programas e qualidade estimulam resultados de equipes enquanto que os sistemas de avaliação, quase que unanimemente, enfatizam o desempenho individual.

\section{Escolha inadequada de multiplicadores}

Como o treinamento é algo contínuo e dinâmico, é crucial a escolha de elementos multiplicadores do conhecimento que se quer disseminar para toda a organização. $O$ erro mais comum que se vê na escolha destas pessoas, e que leva geralmente ao insucesso, está ligado à não-observância de seu perfil realizador. Ou seja, a capacidade destas pessoas gerarem resultados, o que se pode observar em suas funções correntes. Como se diz popularmente, "se você quer que algo seja feito, peça a alguém ocupado". Esta parece ser uma boa indicação inicial para o perfil dos multiplicadores: pessoas ocupadas. Existe, no entanto, uma certa tendência a se indicar justamente aquelas pessoas que dispōe de mais tempo. Será que este "mais tempo" já nãoé um mau indicador de performance?

Por outro lado, não nos iludamos quanto ao aspecto da capacidade de comunicação destes multiplicadores. A função é a da disseminação do conhecimento, formal e informal, portanto, essa característica é também crucial ao sucesso do programa. Em quase todos os processos que participamos, seja como observadores ou como elementos atuantes, confrontamo-nos com essa questão. Normalmente, passamos por duas ou três seleções antes de chegar à equipe desejada de multiplicadores.

\section{Descuido com a motivação}

When I'm right no one remembers, when I' $m$ wrong no one forgets ${ }^{12}$ Esta frase, afixada em um famoso e popular bar paulistano, ilustra bem como se sentem as pessoas em empresas que ainda têm a visão antiga de gestão, ou seja, aqui temos as pessoas que pensam, e as pessoas que fazem!!!

Ainda segundo Osterman ${ }^{13}$, Não se pode esperar que as pessoas continuem contribuin- do com suas idéias se não forem recompensadas por isso". Parece inacreditável, mas ainda se deixa de lado o aspecto motivacional envolvido em programas de qualidade. Cada um precisa sentir que também será beneficiado pela qualidade. Podemos fazer isto de várias formas, desde a mais simples que é mostrar claramente os benefícios para as pessoas, até as mais sofisticadas que envolvem prêmios e recompensas até financeiras.

$O$ reconhecimento do resultado obtido ${ }^{14}$ ainda continua sendo a forma mais eficaz de se motivar colaboradores. A desconsideração por esta simples regra é um dos caminhos mais rápidos para o fracasso de programas de qualidade.

As pessoas percebem se os níveis superiores estão motivados ou não, $e$ isto pode ser um elemento altamente positivo ou altamente negativo. Não estamos falando só em discurso, mas nas atitudes perante a qualidade, nas demonstrações contínuas, por todos os níveis de gestão, de seu interesse pelos resultados do programa.

\section{CONCLUSÃO}

De uma maneira geral, pode-se afirmar que todos os casos de insucesso em implantação de programas de qualidade estão associados a um ou mais dos fatores aqui apresentados. Em geral, são mais de um fator agregados que causam os problemas ou o atraso no atingimento das metas. Como analisamos em cada um dos itens, as soluçōos são relativamente simples e evidentes, o descuido com esses itens é que causa o insucesso.

Olhando pelo prisma do sucesso, podemos também dizer que as empresas que estão colhendo os frutos da qualidade são aquelas que cuidaram destes mesmos citados fatores com esmero, dedicação e persistência.

Obviamente, o objetivo deste texto não é criar uma fantasia sobre as dificuldades de se implantar qualidade, mas sim de fazer um alerta sobre os pequenos problemas, situaçōes e comportamentos que podem pôr a perder uma boa intenção. •

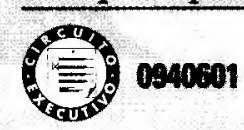

12. Quando estou certo ninguém se lembra, quando estou errado ninguém se esquece. Bar do Leo, São Paulo.

13. Business Week, Oct. 17, 1994.

14. KONDO,Y. Human motivation. Tokyo: $3 A$ Corporation, 1991.

0 autor gostaria de agradecer ao professor Marilson Alves Goncalves pelas pacientes rovisóes $\theta$ inúmeras sugestoos. 